Extract from:

Education in a Changing Environment $17^{\text {th }}-18^{\text {th }}$ September 2003

Conference Proceedings

\title{
Blended Learning in Practice
}

\author{
Chris Procter, c.t.procter@salford.ac.uk
}

\begin{abstract}
This paper is in two parts. Firstly it attempts to create a definition of blended learning. It argues that blended learning need not be seen as the province of technical experts or of distance-learning students. Blended learning is simply the effective combination of different modes of delivery, models of teaching and styles of learning. The paper goes on to outline the development of a part-time degree in Information Technology using blended learning. The experience of this development and subsequent implementation may be of value elsewhere in genuinely encouraging widening participation in higher education.
\end{abstract}

Keywords: e-learning, blended learning, Virtual Learning Environment (VLE)

\section{Introduction}

This paper is written in the midst of the debate about the government target that $50 \%$ of 18-30 year-olds should attend higher education. This is accompanied by the second debate concerning University fees. In spite of the fact that the Government White Paper 'The Future of Higher Education' (DfES 2003) discusses their cause, part-time students are largely lost in the debate. The British workforce is filled with millions who left school when less than $20 \%$ of the population attended higher education. Many of these workers require qualifications to progress in work and are keen and willing to pay. The level of their fees is exempt from Government rules. They must be included in genuine efforts to widen participation and the University of Salford is well placed to achieve this. The University has a long and proud history of part-time study, and providing for the needs of industry in the north-west. The provision of such programmes is an essential part of the University's mission. This paper argues that blended learning is especially suitable for part-time students and for the University.

\section{Definition of Blended Learning}

It is widely thought that the development of a blended learning programme requires a) substantial time and b) substantial expertise. The same arguments have been made in relation to e-learning. A discussion of the definition of blended learning is provided in an attempt to counter these myths.

\section{Is Blended Learning Distance Learning?}

As with all new terms there is no established definition of blended learning. Smith (2001) defines blended learning thus:

A method of educating at a distance that uses technology (high-tech, such as television and the Internet or low-tech, such as voice mail or conference calls) combined with traditional (or, stand-up) education or training.

Identifying blended learning (or e-learning) with distance-learning is a mistake that has significant implications for programme design and delivery. The design of distancelearning requires that all learning outcomes are anticipated and this may require 
Extract from:

Education in a Changing Environment $17^{\text {th }}-18^{\text {th }}$ September 2003

Conference Proceedings

expertise beyond the scope of most academics. Distance learning therefore involves substantial development time and a project management approach that is essentially sequential. The consequence is that flexibility is impaired. In practice all teaching and learning includes some element of distance learning. It is the art of programme design teams to decide what proportion this should be and what activities are best conducted by distance (Procter, 2002). It is more helpful to define e-learning as 'the delivery of learning with the assistance of interactive, electronic technology, whether offline or online' (Institute of IT Training). In other words neither e-learning nor blended learning need be the same as distance learning. Thus a simpler description of blended learning is the combination of modes of delivery including e-learning. Such an initial definition allows for the development of a programme that avoids some of the problems associated with the development of 'pure' distance learning.

\section{Is Blended Learning the Domain of Technical Wizards?}

Literature concerning blended learning frequently assumes technical expertise beyond the reach of most academics. Orey (2002) defines blended learning as:

From the designer perspective, blended learning is the organization and distribution of ALL available facilities, technology, media and materials to achieve an instructional goal even when many of these things may overlap considerably. From the learner perspective, blended learning is being able to choose among the provided learning experiences to achieve my individual learning goals while matching my preferred learning style.

Orey's definition seems complex and thus expensive and unrealistic. Is the academic really expected to be comfortable with all facilities, technology, media and materials? This paper would contend that an understanding of what works in teaching and learning is of far more value to an academic than extensive technical expertise. This understanding in turn comes from experience and research leading to effective practice. The most important contribution that has been made by e-learning is not the technology per se but the fact that it has forced open a debate into teaching and learning.

Thus we can develop further our definition of blended learning above and suggest that blended learning is the effective combination of different modes of delivery, including e-learning.

\section{Models of Learning}

The assumption of technical expertise on the part of the designer is entwined with Orey's assumption that teaching and learning is the achievement of 'instructional goals'. Literature and tools in the field of blended learning frequently have origins in such a didactic model of teaching and learning. In this model 'learners are told about the world and are expected to replicate its content and structure in their thinking' (Duffy and Jonassen 1991). However, there are other well established models of teaching and learning. The best known opposite to the didactic model is the constructivist model where 'knowledge and truth are constructed by people and do not exist outside the human mind' (Duffy and Jonassen 1991). This model is more closely associated with problem based learning and origins in the work of Dewey and others. It is not the purpose of this paper to describe the debate concerning learning models which is ably 
Extract from:

Education in a Changing Environment $17^{\text {th }}-18^{\text {th }}$ September 2003

Conference Proceedings

done elsewhere (see Tam 2000). It is probable that a combination of instruction and construction will continue to prevail for a number of reasons, including purely pragmatic reasons of cost and benefit. The designer of a blended learning programme needs to consider what elements of the blend best achieve this mix of learning models. The definition of blended learning above can be modified in the light of this discussion as follows:

blended learning is the effective combination of different modes of delivery and models of teaching.

Oleg Liber (2003) argues that Virtual Learning Environments (VLEs) such as Blackboard and WebCT are strongest at supporting the delivery of course materials and weaker at supporting social construction. We could postulate that physical attendance at University still offers the best opportunities for student-student and student-staff interaction.

\section{Learning Styles}

Not all students have the same learning style. Especially well known work in the field of learning styles includes the work of Honey and Mumford, and Fleming and Mills. Fleming (2001) classifies learners using the VARK model; Visual, Aural, Read/Write, Kinesthetic. The use of all possible facilities and technologies as suggested by Orey can of course assist learners with different learning styles. Thus a programme that includes graphical materials published on the web may appeal to a Visual learner, and if combined with lectures and tutorials may additionally appeal to an Aural learner. In practice the costs in comparison to benefits will always have to be considered in accommodating different learning styles. We now arrive at a better definition of blended learning:

\section{Blended learning is the effective combination of different modes of delivery, models of teaching and styles of learning.}

The next section describes the initial efforts conducted by the Information Sytems Institute (ISI) at the University of Salford, to create a programme using blended learning.

\section{Development of BSc IT}

The ISI has been operating part-time programmes for many years, including a part-time BSc in Business Information Systems. The experience of operating this programme has highlighted a number of delivery problems. The most important of these is that at least one half of those making enquiries were unable to commit to the daytime attendance requirement of the programme. There is little tradition of day release in this sector. Students attending the part-time degree also struggled to cope with the inflexibility of modules that were originally designed for (and sometimes shared with) full-time students. At the same time it has been clear that part-time students provide tremendous support to each other a feature vital to preserve in any programme development.

In 2003 a new part-time BSc in Information Technology was developed that seeks to combine this experience with our knowledge of blended learning. The aim has been to 
create a programme with relevant content delivered flexibly. It is thus genuinely student-centred in its approach. This development has received funding from the European Union Social Fund (ESF) in recognition of the support it would provide to employees of Small- and Medium-sized Enterprises (SMEs). The programme has a number of key features:

- Attendance requirement is one evening per week. This takes place in secure, good quality teaching accommodation with good access to transport and parking as well as basic University facilities such as catering and computer use;

- All course content is available on the World Wide Web. Internet access is a condition for enrolment on the programme;

- The University supported VLE is the tool used for the delivery of course materials and for other aspects of course support and information, for example discussion boards;

- All modules are either 20 or 40 credits, including an optional 40 credit Work Based Project module at level 2, and a mandatory 40 credit Dissertation at level 3 which may also involve work based research and development. In total therefore 80 credits of a total of 360 for BSc Hons could be conducted wholly in the workplace;

- Sub-honours degree level qualifications are built in (and currently being developed further). BSc Honours would typically take 5 years;

- Students are encouraged to seek Accreditation for Prior Experience and Learning (APEL) at level 1. Entry directly into level 2 is possible. APEL at more advanced levels is a much more complicated issue, not least because of the contribution of modules at level $2 \& 3$ to University awards and also the issue of pre-requisites;

- Teaching assistants (who are also studying for postgraduate qualifications) are employed to provide online and offline support to students on the programme.

\section{Attendance}

From both the staff and student point of view, it is most important that the students make valuable use of their time when present at the University. Attendance for one evening per week offers students opportunities for dialogue with each other and with staff. This also allows staff the opportunity to deliver the syllabus in a way that is responsive to student feedback. If well designed, this time can enhance the opportunities for both social construction (Vygotsky, 1978) and conversational learning (Laurillard, 1993). This gives the programme an advantage over distance-learning programmes.

It is also important that students are not required to attend to conduct activities that could be done remotely. It is the objective both at module and programme level that all information that can be provided remotely is provided through the VLE. This applies both to issues of course content and issues of university administration and quality assurance. Clearly at such an early stage this is not fully implementable. For example, at a school level the ISI does not yet have a process for online submission of Personal Mitigating Circumstances. At a university level, there is no provision of online registration and payment. In both examples change is now being discussed. 
Extract from:

Education in a Changing Environment $17^{\text {th }}-18^{\text {th }}$ September 2003

Conference Proceedings

\section{E-Learning}

Students on equivalent full-time modules would have approximately three times as many hours on their timetable. The difference is accounted for by the extensive provision of e-learning materials. The programme team is making full use of the VLE. Each module has its own area on the VLE, together with an area for the programme as a whole. Modules include learning units. These are folders containing an introduction to the topic, links to references in text books and to the Web, and formative or summative exercises. Modules additionally have many other resources such as staff contact details, reading lists, assessment details as well as areas for students to discuss course content online.

\section{Module Size}

The former part-time BSc offered by the ISI made extensive use of 10 credit modules (where 120 credits constitutes completion of a level). Such small modules typically include numerous relatively small assessments with short bunched deadlines. This has led in the past to part-time students failing through being over-assessed rather than through lack of ability. This in turn is the reason why the minimum module size on the new programme is 20 credits. At the most in a given semester the student would be studying 2 subjects only.

\section{Student Support}

It has always been apparent that the support services provided by a University whose main business is full-time undergraduates (69\% of the total at Salford in 2001-2) are not necessarily as useful to part-time students. Anecdotal evidence suggests that part-time students are less likely to use either the students union or services provided by the University. In some cases this is because they are not available out of office hours, in some cases because the students are more self-sufficient and in some cases because of lack of knowledge of what is available. It is generally more difficult for part-time students to simply 'drop in', so that appointments are nearly always necessary. Teaching assistants provide first level support, just as postgraduate assistants have traditionally supported full-time student tutorials. This can be by email, telephone or in person and may involve referral to either academics or support services.

\section{Further Research}

The paper has described a programme at the early stages of delivery using a blended learning model. Research will be conducted into both the student and staff perspective concerning the efficacy of the mode of delivery. Primary research will be undertaken by Graduate Teaching Assistants (GTAs) who have been employed to provide teaching support to the programme, whilst conducting teaching and learning research. The likelihood is that they will use action research in order to be able to influence the delivery in future years. This can help to ensure that broad objectives given above, such as the achievement of social construction in face-to-face sessions, are achieved within the delivery of the programme. The problems and achievements will be reported in due course. 
Extract from:

Education in a Changing Environment $17^{\text {th }}-18^{\text {th }}$ September 2003

Conference Proceedings

\section{Conclusion}

The design of the programme is student-centred and takes account of the special requirements of part-time students. The combination of class contact with e-learning used within the programme together with the possibility of accommodating different learning models and styles fits within the definition of blended learning given above. At the time of writing, the programme has achieved its target of an initial enrolment of 40 students.

The programme content itself and intermediate qualifications are subject to continual review and improvement e.g. the feasibility of nesting a Foundation Degree within the programme is currently being investigated. There will be thorough evaluation conducted by the staff involved in the programme following the initial year of delivery. We will seek to generalise the lessons learnt with a view to the development of further undergraduate and postgraduate programmes. It has already been suggested that the blended learning model described above would neatly fit the delivery of a part-time taught doctorate - watch this space!

\section{References}

Duffy, T. M. and Jonassen, D.H. (1991) New implications for instructional technology? Educational Technology 31(3), 7-12

Honey, P. and Mumford A. (1992) The manual of learning styles 3rd ed. Maidenhead Laurillard, D. (1993) Rethinking university teaching: a framework for effective use of educational technology. Routledge, London

Liber, O (2003) paper on e-learning at e4SME conference, Wigan UK (under publication)

Procter, C. (2002) Proportion, pedagogy and processes: the three p’s of e-learning. Conference of International Association of Information Management, Barcelona.

Tam M. (2000) Constructivism, Instructional Design, and Technology: Implications for Transforming Distance Learning. Educational Technology and Society 3(2)

Vygotsky, L.S. (1978). Mind in Society. Cambridge MA: Harvard University Press DFES (2003) http://www.dfes.gov.uk/highereducation/hestrategy/ White Paper on Higher Education 2003

http://lpsl1.coe.uga.edu/publications/eera-blended/blended.html Orey, M 'One year of Online Blended Learning: Lessons Learned' 2002

http://www.vark-learn.com Fleming, N 2001

http://www.gwsae.org/Executiveupdate/2001/March/blended.htm, Smith, J.M. (2001).

Blended Learning: An old friend gets a new name 